\title{
Editorial \\ Inflammatory cells and bone loss in rheumatoid arthritis
}

\section{David R Haynes}

Discipline of Pathology, School of Medical Sciences, University of Adelaide, North Terrace, SA 5005, Australia

Corresponding author: David R Haynes, david.haynes@adelaide.edu.au

Published: 22 June 2007

Arthritis Research \& Therapy 2007, 9:104 (doi:10.1186/ar2213)

This article is online at http://arthritis-research.com/content/9/3/104

(c) 2007 BioMed Central Ltd

See related research article by Poubelle et al., http://arthritis-research.com/content/9/2/R25

\begin{abstract}
Pathogenic bone erosion is often associated with inflammation. The destructive bone erosion that is often seen in rheumatoid arthritis is probably due to the close proximity of inflamed tissues to bone. Over the past decade, major advances have been made in our understanding of the factors that are crucial in regulating osteoclast bone resorption. It is not surprising that these factors are expressed by inflammatory cells that are present in the rheumatoid joint. It now appears that we can add neutrophils to the list of inflammatory cells found in the inflamed rheumatoid joint that express factors that regulate bone erosion.
\end{abstract}

The report that neutrophils may contribute to regulation of bone remodelling in rheumatoid arthritis (RA) [1] highlights the fact that a variety of inflammatory cells are responsible for the induction of bone loss observed in inflammatory diseases. Bone erosion and inflammation are not distinctly different processes, and there is a close relationship between the two. The fact that similar factors stimulate both processes means that when inflammation occurs near bone, such as in RA, local erosion takes place.

The past two decades have witnessed the discovery of several important soluble factors and cell surface molecules that are involved in mediating osteoclast differentiation and bone resorption. Of most importance are receptor activator of nuclear factor- $\kappa B$ ligand (RANKL) and its receptor RANK. It is interesting to note that RANK/RANKL interactions were first described in relation to activities of antigen-presenting cells [2], and it was the fact that neutrophils may act as antigenpresenting cells that provided the impetus for the study conducted by Poubelle and coworkers [1]. In relation to bone metabolism, RANKL and RANK were initially identified on osteoblasts and precursor osteoclasts, respectively, and are crucial for osteoclast formation $[3,4]$. It is widely accepted that RANKL, together with macrophage colony-stimulating factor, are the most important factors that stimulate osteoclast formation from precursor monocyte/macrophages. The relative levels of RANKL and osteoprotegerin (OPG), which is the natural soluble inhibitor of interactions between RANK and RANKL [3-5], play a vital role in determining whether bone is formed or lost. Whereas the tumour necrosis factor (TNF)/TNF receptor 'like' molecules RANK, RANKL and OPG are crucial for physiological osteoclast formation, it is now recognized they are key regulators of osteoclast activity in disease.

RANKL is present at high levels in RA synovial tissues as compared with healthy or osteoarthritic synovial tissues [6], and several inflammatory cell types are probably responsible for ectopic production of RANKL in synovial tissues adjacent to bone. In RA synovial tissues, activated lymphocytes expressing CD3 are a predominant cell type that expresses RANKL protein [7]. RANKL may also be produced by other cells of the RA joint, such as synovial fibroblasts [8], chondrocytes [9], endothelial cells [10] and possibly activated macrophages [11]. It appears that we can now add neutrophils to our list of inflammatory cells that secrete RANKL. Poubelle and coworkers [1] showed that neutrophils express RANKL on the cell surface, and therefore neutrophil stimulation of osteoclasts may only have very localized effects because cell-cell contact is required.

Many inflammatory cytokines that are found in the inflamed RA joint are known to stimulate osteoclast formation. However, the ability of interleukin-4 to stimulate RANKL production reported by Poubelle and coworkers [1] is interesting because this cytokine is known to inhibit osteoclast formation [12]. In addition, it was reported by Poubelle and coworkers [1] that neutrophils in RA synovial fluid also secrete OPG. However, neutrophil derived OPG may not markedly influence OPG levels as OPG in RA synovial tissues [13] and synovial fluid [14] is lower than OA control samples. The reduction in OPG expression in the rheumatoid joint is also more consistent with

$\mathrm{OPG}=$ osteoprotegerin; $\mathrm{RA}=$ rheumatoid arthritis; RANK = receptor activator of nuclear factor- $\mathrm{KB} ; \mathrm{RANKL}=$ receptor activator of nuclear factor$\kappa \mathrm{B}$ ligand; TNF = tumour necrosis factor. 
increased ratios of RANKL to OPG and bone resorption observed in active RA [15].

The expression of RANK on the surface of neutrophils may be related to the reported antigen-presenting activities of neutrophils. In addition, expression of TNF receptor-associated factor6 by these cells suggests that cells can be activated through the RANK/RANKL pathway, possibly in an autocrine manner.

With the extensive immunohistological studies conducted in RA synovial tissues, it seems surprising that RANK, RANKL, or OPG expression by neutrophils has not previously been reported. However, when one carefully examines the tissues used, there are very few neutrophils to be seen. These tissues have the hallmarks of chronic inflammation, containing many macrophages, lymphocytes and fibroblasts. The influx of neutrophils associated with active RA was not seen in the synovial tissues of these patients, but it might have been present in the synovial fluid. Importantly, RANKL expression by activated neutrophils is likely to induce the rapid bone erosion that occurs in septic arthritis [16]. Neutrophils are also thought to play a key role in the degeneration of articular cartilage that takes place in septic arthritis, and it could be speculated that RANKL derived from neutrophils may in some way be involved. However, neutrophils are unlikely to have a direct effect through release of RANKL because although RANK is expressed by chondrocytes, RANKL has been reported not to activate human articular chondrocytes [9].

The simple view that neutrophils are leucocytes that are exclusively involved in acute inflammatory responses and act as the first line of defence against invading pathogens needs modification. The neutrophil presence in a number of chronic inflammatory diseases, such as RA, indicates that these cells may play an important role in chronic inflammation. It is increasingly apparent neutrophils exhibit many of the properties of their fellow phagocytic cells of the monocyte/ macrophage lineage. Their rapid secretion of many factors that are also released by macrophages, lymphocytes and fibroblasts indicates that they can play similar roles in chronic inflammation. Many of these factors are pivotal in causing tissue destruction, either directly or indirectly.

We are still to determine the importance of the neutrophil in regulating the bone destruction that occurs in RA and other chronic inflammatory conditions. However, when inflammation flares take place in RA, large numbers of activated neutrophils are rapidly recruited to the joint and aggregate in the synovial fluid. The rapid release of factors that regulate bone metabolism, such as RANK, by these cells could provide a large, transient increase in RANKL levels in the joint, supplementing that normally provided by the chronic inflammatory cells in synovial tissues. This may result in rapid stimulation of bone erosion during disease flares in active RA.

\section{Competing interests}

The author declares that they have no competing interests.

\section{Acknowledgements}

This work was supported in part by the National Health and Medical Research Council of Australia. The author wishes to acknowledge the help of Christopher Holding in the preparation of this manuscript.

\section{References}

1. Poubelle PE, Chakravarti A, Fernandes MJ, Doiron K, Marceau AA: Differential expression of RANK/RANK-L/OPG by synovial fluid neutrophils from patients with rheumatoid arthritis and normal human blood neutrophils. Arthritis Res Ther 2007, 9: R25.

2. Wong BR, Josien R, Lee SY, Sauter B, Li H-L, Steinman RM, Choi $Y$ : TRANCE (tumor necrosis factor [TNF]-related activationinduced cytokine), a new TNF family member predominantly expressed in T cells, is a dendritic cell-specific survival factor. $J$ Exp Med 1997, 186:2075-2080.

3. Yasuda H, Shima N, Nakagawa N, Yamaguchi K, Kinosaki M, Mochizuki S-I, Tomoyasu A, Yano K, Goto M, Murakami A, et al:: Osteoclast differentiation factor is a ligand for osteoprotegerin/osteoclast inhibitory factor and is identical to TRANCE/ RANKL. Proc Natl Acad Sci USA 1998, 95:3597-3602.

4. Lacey DL, Timms E, Tan H-L, Kelley MJ, Dunstan CR, Burgess T, Elliot R, Colombero A, Elliot G, Scully S, et al.: Osteoprotegerin ligand is a cytokine that regulates osteoclast differentiation and activation. Cell 1998, 93:165-176.

5. Yasuda H, Shima N, Nakagawa N, Mochizuki S-I, Yano K, Fujise N, Sato Y, Goto M, Yamaguchi K, Kuriyama M, et al:: Identity of osteoclastogenesis inhibitory factor (OCIF) and osteoprotegerin (OPG): a mechanism by which OPG/OCIF inhibits osteoclastogenesis in vitro. Endocrinology 1998, 139:13291337.

6. Gravallese EM, Manning C, Tsay A, Naito A, Pan C, Amento E, Goldring S: Synovial tissue in rheumatoid arthritis is a source of osteoclast differentiation factor. Arthritis Rheum 2000, 43: 250-258.

7. Horwood NJ, Kartsogiannis V, Quinn JM, Romas E, Martin TJ, Gillespie MT: Activated T lymphocytes support osteoclast formation in vitro. Biochem Biophys Res Commun 1999, 265:144150.

8. Shigeyama Y, Pap T, Kunzler P, Simmen BR, Gay RE, Gay S: Expression of osteoclast differentiation factor in rheumatoid arthritis. Arthritis Rheum 2000, 43:2523-2530.

9. Komuro H, Olee T, Kuhn K, Quach J, Brinson DC, Shikhman A, Valbracht J, Creighton-Achermann L, Lotz M: The osteoprotegerin/receptor activator of nuclear factor kappaB/receptor activator of nuclear factor kappaB ligand system in cartilage. Arthritis Rheum 2001, 44:2768-2776.

10. Collin-Osdoby P, Rothe L, Anderson F, Nelson M, Maloney W, Osdoby P: Receptor activator of NF-KB and osteoprotegerin expression by human microvascular endothelial cells, regulation by inflammatory cytokines, and role in human osteoclastogenesis. J Biol Chem 2001, 276:20659-20672.

11. Crotti TN, Smith MD, Weedon H, Ahern MJ, Findlay DM, Kraan M Tak PP, Haynes DR: Receptor activator NF $\mathbf{k B}$ ligand (RANKL) expression in synovial tissue from rheumatoid arthritis, spondyloarthropathy, osteoarthritis and normal patients: semi-quantitative and quantitative analysis. Ann Rheum Dis 2002, 61:1047-1054

12. Bendixen AC, Shevde NK, Dienger KM, Willson TM, Funk CD, Pike JW: IL-4 inhibits osteoclast formation through a direct action on osteoclast precursors via peroxisome proliferatoractivated receptor gamma 1. Proc Natl Acad Sci USA 2001, 98:2443-2448.

13. Haynes DR, Barg E, Crotti TN, Weedon H, Atkins GJ, Zannettino A, Ahern MJ, Coleman M, Roberts-Thomson PJ, Kraan MC, et al.: Osteoprotegerin (OPG) expression in synovial tissue from patients with rheumatoid arthritis, spondyloarthropathies, osteoarthritis and normal controls. Rheumato/ 2003, 43:1-12.

14. Skoumal M, Kolarz G, Haberhauer G, Woloszczuk W, Hawa G, Klingler A: Osteoprotegerin and the receptor activator of NFkappa $B$ ligand in the serum and synovial fluid. A comparison 
of patients with longstanding rheumatoid arthritis and osteoarthritis. Rheumatol Int 2005, 26:63-69.

15. Haynes DR, Crotti TN, Loric M, Bain Gl, Atkins GJ, Findlay DM: Osteoprotegerin and receptor activator of nuclear factor kappaB ligand (RANKL) regulate osteoclast formation by cells in the human rheumatoid arthritic joint. Rheumatology (Oxford) 2001, 40:623-630.

16. Sakurai A, Okahashi N, Nakagawa I, Kawabata S, Amano A, Ooshima T, Hamada S: Streptococcus pyogenes infection induces septic arthritis with increased production of the receptor activator of the NF-kappaB ligand. Infect Immun 2003, 71:6019-6026. 